\title{
Design and Implementation of a Low-cost Irradiance - Temperature Data Logging Meter for Solar PV Applications
}

\author{
Emmanuel Ogundimu ${ }^{1}$, Esther Akinlabi ${ }^{1,2}$, Chigbo Mgbemene ${ }^{3}$, Ifeanyi Jacobs ${ }^{3}$ \\ ${ }^{1}$ Department of Mechanical Engineering, University of Johannesburg, Johannesburg, South Africa \\ ${ }^{2}$ Pan African University of Life and Earth Sciences Institute, Ibadan, Nigeria \\ ${ }^{3}$ Department of Mechanical Engineering, University of Nigeria, Nsukka, Nigeria
}

Email address:

216089300@student.uj.ac.za (E. Ogundimu)

\section{To cite this article:}

Emmanuel Ogundimu, Esther Akinlabi, Chigbo Mgbemene, Ifeanyi Jacobs. Design and Implementation of a Low-cost Irradiance Temperature Data Logging Meter for Solar PV Applications. American Journal of Mechanical and Industrial Engineering. Vol. 6, No. 4, 2021, pp. 50-55. doi: 10.11648/j.ajmie.20210604.12

Received: July 14, 2021; Accepted: August 4, 2021; Published: September 7, 2021

\begin{abstract}
The rapid exhausting traditional energy sources and the contemporary constantly intensifying energy entreaty with respects to biological matters have reinforced concentrated research on solar energy novelty. Capturing maximum energy from the sun by applying photovoltaic solar technology is challenging. A limited feature that affect the solar energy harvest of such technology include the photovoltaic material, topographical area of solar irradiances, surrounding temperature and climate, the angle of sun and orientation of the panel. This work presents an automated and low-cost irradiance-temperature $\left(\mathrm{W} / \mathrm{m}^{2}\right)$ logging meter, Low-Cost Sensor (Pyranometer) to measure Solar Irradiance in Nsukka, Nigeria. The core distinctive of this device is the low-cost of all its mechanisms. The design of this device is grounded on by means of temperature sensor DHT11 and phototransistor PT202C. This design was implemented for the periods of 90 days along with standard pyranometer and thermometer installed to two 250 watts photovoltaic (PV) solar panel similar at University of Nigeria, Nsukka. This device enhanced sensitiveness to solar irradiance, permitting a brilliant feedback of the device in a range from approximately 250 to $1200 \times 10^{-9} \mathrm{~m}$. This device incapacitates out dated complications in this kind of device and propositions comparable features to those of thermopile-based irradiance meter and, hence, can be used at all setting up where consistent sizing of solar isolation is required and the overall result indicates that the coefficient of correlation of the solar isolation gotten with the projected device is 0.9996 .
\end{abstract}

Keywords: Device, Low-cost, Phototransistor, Pyranometer, Solar Irradiance

\section{Introduction}

Light can be defined as a radiant energy. Electromagnetic radiation can be viewed as both as a wave and a molecule, contingent upon how it is estimated through space. At the point when light is engaged by a substantial item, its energy is changed into some other structure. The brilliant energy of the unmistakable light makes an electric flow stream in a photographic light meter when its brilliant energy is moved to the electrons as active energy. Everything in nature discharges electromagnetic energy, and solar radiation is energy produced from the sun. The energy of extra-terrestrial solar radiation is appropriated over a wide ceaseless range going infrared beams to ultraviolet beams. The solar radiation can be decomposed into a direct and a diffuse part. Coordinate daylight originates from the piece of the sky that is secured by the sun. This phantom scope of electromagnetic is termed radiometry [1].

Radiometry is the science of estimating light in any bit of the electromagnetic range. Practically speaking, the term is typically restricted to the estimation of infrared, visible, and ultraviolet light utilizing optical instruments while Photometry is the science of the estimation of light' like its evident wonder to the human eye. Figure 1 shows the vitality contained in the sunlight-based range (zone under the bend). The fundamental bit of the vitality from figure 1 , it is possible to believe that all out sun-oriented vitality gather doesn't expose to Sun's brilliant power yet, rather on the sunlight-based radiation. Conventionally, a pyranometer is a 
meter for estimating solar isolation on a typically level surface, in a field of 180 degrees. Estimation of solar isolation per unit of surface $\left(\mathrm{W} / \mathrm{m}^{2}\right)$ is named irradiance. isolation estimation requires, by definition, that the pyranometer's sensor's reaction to radiation fluctuates with the cosine of the edge of occurrence from a line vertical to the outside of the sensor [3]. Is contained between 300 and $1300 \mathrm{~nm}$ wavelength.

\section{Spectrum of Solar Radiation (Earth)}

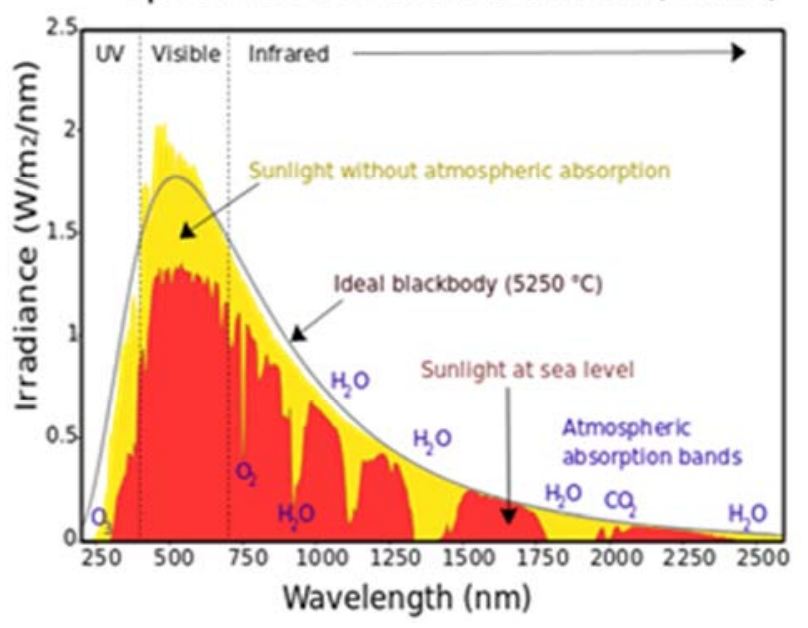

Figure 1. Solar radiation spectrum diagram [2].

That is, the most extraordinary response is gotten when the radiation lands at the sensor oppositely (the sun at its zenith), while no response is gotten when the sun isn't an excess of expelled (a point of rehash of $90^{\circ}$ ) in addition, the response is half of the most insane when the event radiation is at $60^{\circ}$. Thus, it will all things considered be gotten from the definition that a pyranometer must have a "directional" response or, everything considered overall named, a cosine response to enhance the manner by which that its response ought to ideally be in each functional sense unclear from the cosine work. The multifaceted nature between the pyranometer's true blue response and the ideal cosine response is named cosine goof [4].

A central direct pyranometer requires no ability to work and contains thermopile sensor underneath a glass twist. The thermopile ingests all the sun-based radiation which it encounters and makes a pinch of differentiating yield voltage. Pyranometers are essentially used on or near sun energized sheets to have immaculate board planning. Pyrheliometers take after pyranometers yet are planned to evaluate simply sort out shaft sun filled irradiance [5]. They are some of the time used in unclear applications like in sun arranged after systems to ensure that the structure is continually pointed towards the sun. The contraption is generally mounted really on the going with structure, so it is continually assessing direct fragment daylight. Light enters pyrheliometers through reason for blend, which encounters daylight onto a thermocouple in the device. Most pyrheliometers can change over a thermopile's little voltage yield into watts per square meter and either yield or record this data. Quantum sensors are essentially momentous gadgets. The imperativeness yield of run of the mill generators is gained by synchronizing with time; eventually the power execution of a PV module relies upon numerous variables, for example, module temperature, irradiance, and qualities of the module itself [6]. The device which measure the temperature is called thermometer.

The name thermometer was created from the Greek words thermo signifying "warm" and meter, "to measure". Thermometers measure temperature, by utilizing physical materials that is sensitive to heating or cooling [7]. Test type thermometers commonly use a thermistor in the test tip to the sum the temperature. A thermistor is a resistor whose obstruction shifts with temperature. A voltage-divider, produced using a thermistor in course of action with an exactness resistor, is driven by a reference voltage and estimated either single-completed at the midpoint or differentially over the thermistor. Extra accuracy resistors are from time to time used alongside a similar reference voltage in a different circuit to take out errors brought about by the reference voltage drifting after some time. In case the thermistor-divider circuit and the simple to-advanced converter (ADC) use a similar reference voltage, by then the accuracy adjustment resistors are not required. In such a case, the reference voltage is disposed of from the temperature estimation, appropriately facilitating the reference requirements [8].

A thermistor requires a count including a characteristic log, which can exhaust a lot of computational cycles and code space in the microcontroller. Then again, a question table can be used to figure the temperature, a methodology that generally realizes a quicker estimation and dynamically minimized code. In any case, there is an exchange off between the size of the table and the insertion screw up between table sections where expanding the number of centers in the table will diminish the addition blunder. An ADC with 12 bits or more is satisfactory for this estimation, and an addition arrange is discretionary depending upon the estimation extend and needed precision. Advanced thermometers are significantly quicker than mercury thermometers. At times, the thermistor is preheated with the objective that it gets to the last temperature quicker. Normally, judicious calculations are used to choose temperature [9]. The effect of temperature on pyranometer's estimation is additionally exceptional. Even though this effect exists, it is lower in thermopile pyranometers [10-11] than in photodiode gadgets [12]. About coordinating a pyranometer into an instrumentation structure (by and large into any estimating contraption), there is a movement of significant components to contemplate, in particular: simplicity of affiliation, signal debasement in view of the transmission technique [13]. Many authors had worked on the design and of pyrometer using thermopile as a sensor, photodiode as sensor, phototransistor as sensor [1-13] and using photovoltaic solar panel as a reference but none or little has been recorded on the design and implementation of pyranometer and digital thermometer as their exist a relationship between irradiance and ambient temperature in a photovoltaic solar panel. 
To accomplish the goal projected in this study, structuring and assembling a phototransistor-based irradiance meter and digital thermometer with analogous features to those of a thermopile-based gadget, also integrating substantial association, determining and user interface design utilities. The design of this device is grounded on by means of temperature sensor DHT11 and phototransistor PT202C.

DHT11 generally called AM2302 yield adjusted automated sign. It applies specific motorized sign get-together framework and wetness recognizing improvement, guaranteeing its steady quality and persistence. Its distinctive sections relate to 8-piece A microcircuit. Individual sensor of this prototypical is thermal reformed and balanced adjustment compartment and the alteration coefficient is secure in sort of program in OTP reminiscence, when the sensor is remembering, it will insinuate coefficient from memory. Negligible size and low use and long transmission distance $(100 \mathrm{~m})$ connect with AM2302 to be fit in a wide extent of heartless application events. Single-push bundled with four pins, making the alliance remarkably pleasing.

\section{Background}

Irradiance meter are broadband apparatuses that record

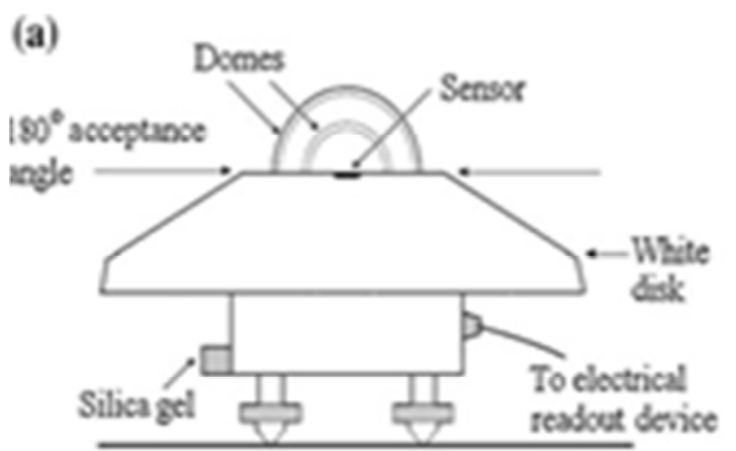

overall sun arranged isolation drawing nearer from а $2 л$ solid edge on a planar surface. A distinctive irradiance meter is mimetically addressed in Figure 2 (a). It involves a white hover for obliging the affirmation edge to 2 л strong edge on a planar surface. Direct spreads produced from glass. The twofold curves safeguard the sensor from thermal convection; secure it in contrast to atmosphere risk and purpose of detention the extraordinary affectability of the apparatus in the wavelength of $0.29-2.8 \mu \mathrm{m}$. A cassette of silica gel within the vault ingests water rage. An irradiance meter can be in like manner used to check the diffuse isolation gave that the responsibility of the prompt shaft section is discarded.

For this, a bit of covering plate can be mounted on a robotized daylight-based tracker to certify that the irradiance meter is reliably hidden. Then again, a sleuth ring may avert the quick fragment isolation from landing at the sensor whole day long Figure 2 (b). Since the step by step most noteworthy Sun raise edge changes bit by bit, it is critical to change sporadically (days slack) the elevation of the sleuth ring. Moreover, considering the way that the shadow ring furthermore hinders a bit of the prolix isolation, it is essential to address the purposeful characteristics. The degree of the prolix isolation obstructed by the sleuth ring changes annually with its spot and climatic circumstances $[15,16]$.

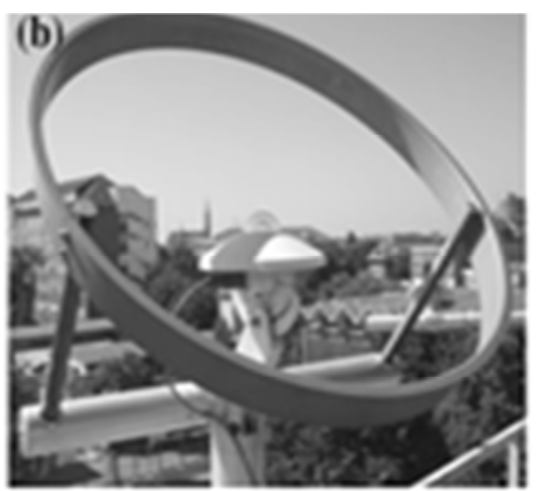

Figure 2. (a) Representation of a pyranometer. (b) First class pyranometer LPPYRA 12 [14].

All the above vulnerabilities ought to be recognized for a good-portrayed apparatus. Some apparatuses are good for atmospheres, isolation, and sun-oriented positions; consequently, the apparatuses ought to be chosen by their user.

\subsection{Apparatus \& Procedure}

As clarified previously, the motivation behind this paper is to structure and manufactured a Solar Radiation Sensor ready to gather irradiance data utilizing minimal effort parts. To accomplish this, the plan of the minimal low-cost device which will measure, and data logged irradiance, temperature and humidity simultaneously, will be partitioned into three phases: the determination of the sensor, the structure of the electronics and the data logger and the structure of lodging to encase the sensor and microcontroller.

\subsection{Selection of the Sensor}

In the neighborhood market, there are four choices of sensors for radiometry device: light dependent resistors (LDR), photo transistors, photo diodes, and reference cell. The choice will be taken dependent on specialized highlights of these four devices. Subsequently, their temperature factor should be balanced expanding the intricacy of the structure.

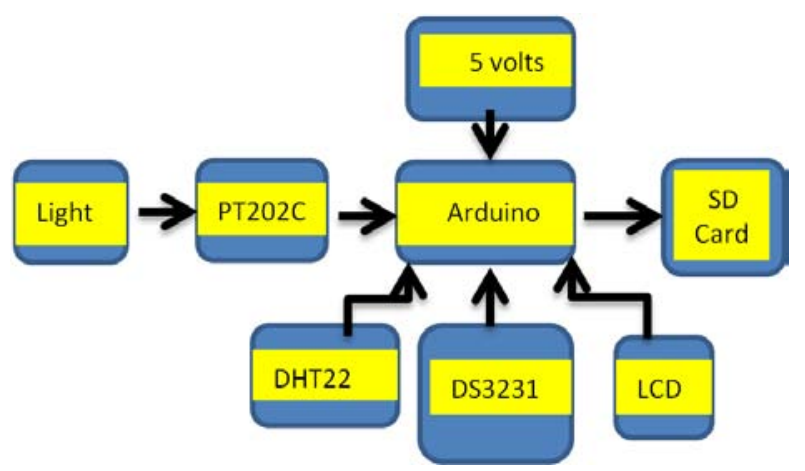

Figure 3. Architecture implemented of a solar irradiance meter with SD (Secure digital) card real time data logger system. 
Table 1. Different types of sensors used in irradiance meter.

\begin{tabular}{llllll}
\hline & Thermopile & Photo-diode & Photo-transistor & Solar Cell & LDR \\
\hline Common type & & SFH 229 & PT202C & & $550 \mathrm{~nm}$ \\
spectral peak & $550 \mathrm{~nm}$ & $850 \mathrm{~nm}$ & Er & & \\
Sensitivity range & 300 to $2800 \mathrm{~nm}$ & $400-1100 \mathrm{~nm}$ & $350-1250 \mathrm{~nm}$ & $350-1150 \mathrm{~nm}$ & Low \\
Cost & Expensive & Moderate & Moderate & Moderate & Low \\
Accuracy & Highest & Moderate & High & Moderate & Low \\
Response time & Very fast & Average & Fast & & \\
\hline
\end{tabular}

This design employs the breakthrough experienced with the use of optoelectronic devices PT202C unlike the solar radiometers described above that uses some manual technology, temperature and humidity sensor (DHT11) unlike the hygrometers and thermometers, SD (Secure digital) card module, RTC module with microcontroller technology to be programmed in $\mathrm{C}++$ language are combined together in the control of electronic processes and systems to calculate, redefine, and produce the output as shown figure 3 . Highlights of improvement over old methods are:

The use of a microcontroller in the design of the solar irradiance meter using ATMEGA328P Arduino NANO microcontroller and PT202C sensors.

To include a temperature and humidity module (DHT11) to be able to measure temperature and humidity alongside the irradiance measurement to observe the effect on solar cells.

To include a real time clock system that would count and keep record of time of every measurement made using the RTC (Real time clock) module.

To also include SD card data logging shield module to keep record of time and irradiance measurement made on SD card in MS EXEL format.

To also include an LCD (liquid crystal display) to display the time and irradiance measurement taken on a 20 by 4 LCD screen.

To make the design durable by using a type $6 \mathrm{~F} 229 \mathrm{~V}$ battery.

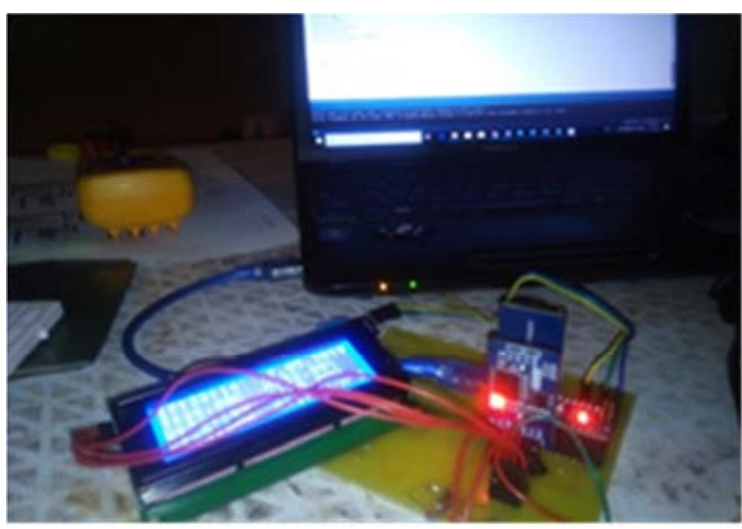

Figure 4. The prototype designed and programmed.

DHT11 is a solitary wire advanced dampness and temperature sensor, which gives relative mugginess in rate and temperature in values sequentially. DHT11 sensor gives stickiness esteem in rate in relative mugginess (20 to $90 \%$ $\mathrm{RH})$ and temperature esteems in degree Celsius $\left(0\right.$ to $\left.50^{\circ} \mathrm{C}\right)$
DHT11 sensor utilizes resistive moistness estimation segment and NTC temperature estimation part. To begin correspondence with DHT11, first, we should send the beginning heartbeat to the DHT11 sensor. This gadget was planned as a smaller, minimal effort, battery-fueled, rough sun-oriented irradiance observing framework that can without much of a stretch be utilized. The plan depends on a strong state microcontroller that is customized to peruse yield from a phototransistor PT202C, stickiness/temperature sensor DHT11, RTC module DS3231 and SD card module which is being processed to display the results on the $20 \times 4$ LCD and stores it inside a memory card in excel format as shown in figure 4 . The design is smaller, more durable and operates at lower bias voltage. The coding for the ATMEGA328P microcontroller was completed with the Arduino IDE compiler from Arduino. The outer $16 \mathrm{MHz}$ RC oscillator was utilized as the clock hotspot for the ATMEGA328P microcontroller. The chip was customized with a low breaker byte of significant worth 0XE4 and high wire byte of significant worth $0 \mathrm{xC}$. The lock combine bytes were unused as they were a bit much for this structure. The fundamental capacity was to introduce the necessary factors, registers and library capacities. In the primary circle, the RMS estimation of 512 ADC tests was processed and dependent on a coordinating "if" condition, the comparing readings esteem was resolved and showed. The sensors take their individual estimations, conveys it to the microcontroller to be handled. The outcomes from there on will be shown on the 20x 4 LCD nearby with the present time and date. The information taken is put away on the memory card inside the SD card module in exceed expectations design after like clockwork.

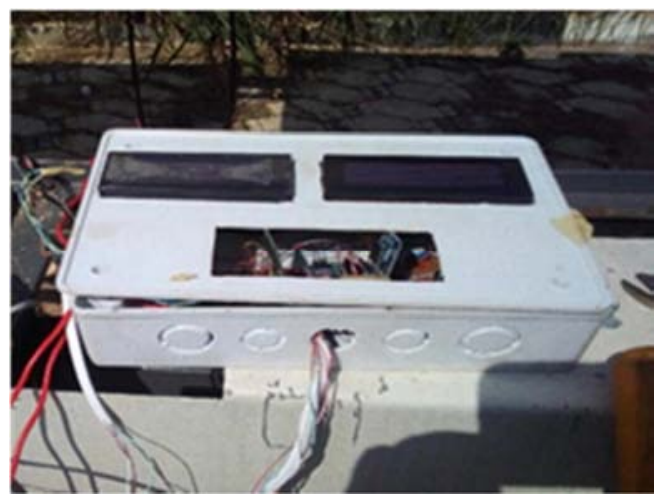

Figure 5. The final prototype of the proposed irradiance meter. 
The design is cased inside a $30 \times 15 \mathrm{~mm}$ adaptable box as shown in figure 5.

\section{Results and Discussion}

The proposed device was installed on a 250 watts PV solar panel along with SM206 standard irradiance meter and AT4208 multi-channel temperature meter for a period of 10 hours in order to measure and record global horizontal irradiance and ambient temperature as shown figure 6 .

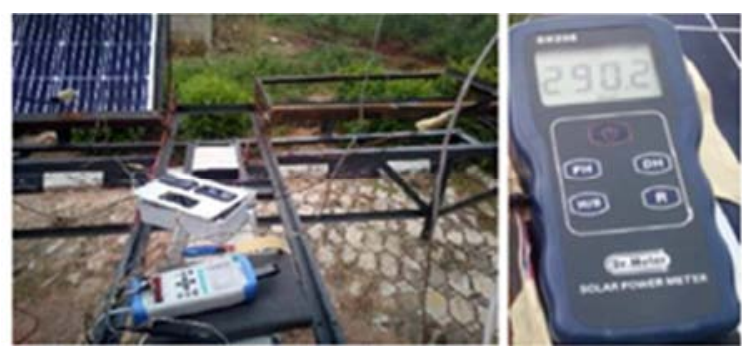

Figure 6. Testing and Calibration of the prototype.

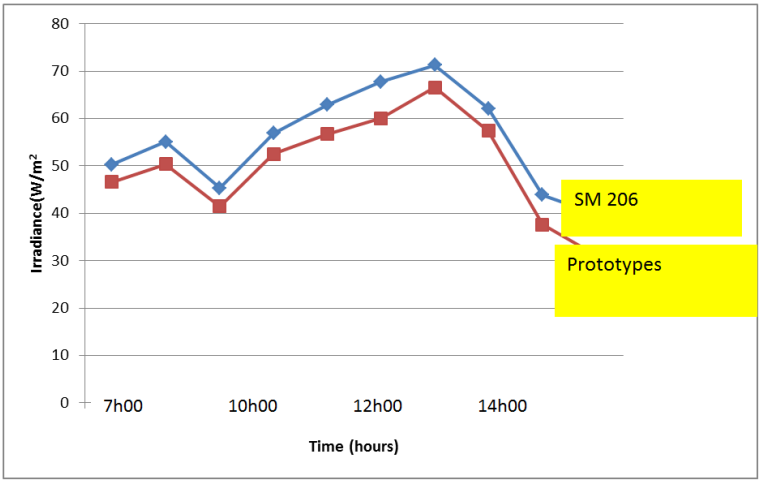

Figure 7. Graph of Time against Irradiance.

The data obtained from the prototype of proposed device were compared with those generated by the SM206 Solar power meter and AT4208 multi-channel temperature meter as indicated in figures $7 \& 8$.

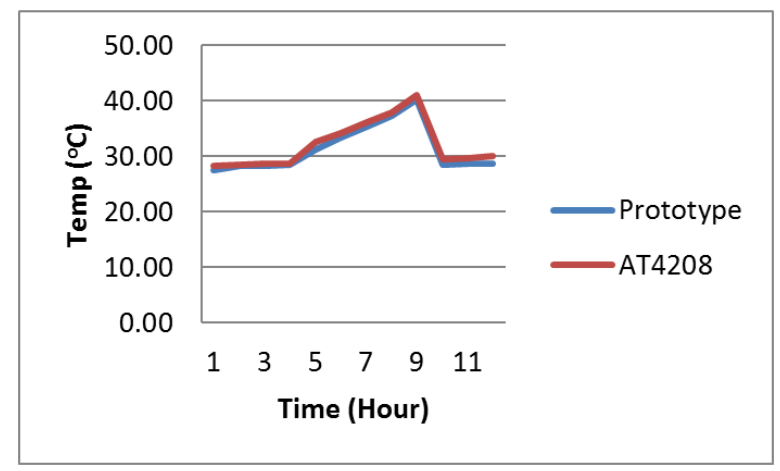

Figure 8. Graph of Time against Ambient Temperature.

The values obtained from the prototype irradiance meter are very close to the one obtained in secondary standard irradiance meter as shown figure 7. Also figure 8 showed the relationship between the ambient temperature measured by the proposed prototype and standard temperature meter.
In Figure 9 (a) to (c) measured the global horizontal irradiance, stated in $\mathrm{W} / \mathrm{m}^{2}$ of the both devices are shown, which obtain a correlation coefficient $\mathrm{R}^{2}=0.99961$, which provides a clue of the relation measure of the degree of rectilinear connotation amid the both devices, as well as the dependability of the premeditated effectiveness.
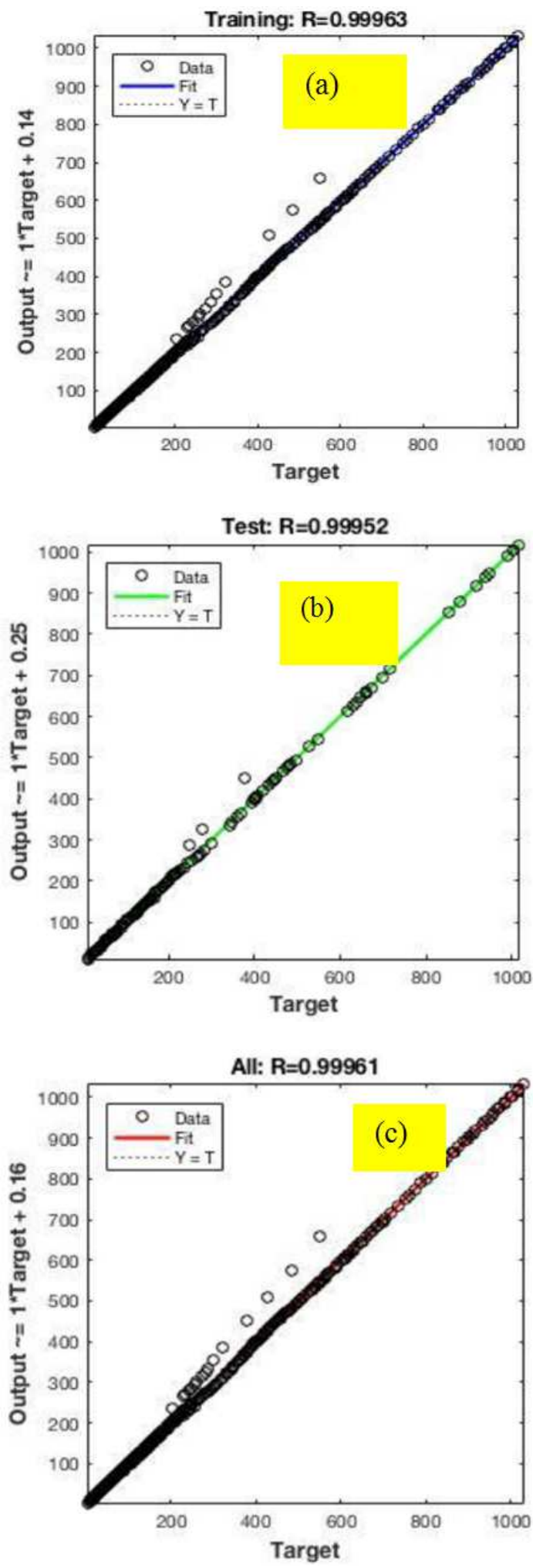

Figure 9. Coefficient of correlation (a) Training (b) Testing (c) Validation. 


\section{Conclusion}

This paper displays the design, development, and testing of a photo transistor-based irradiance meter for photovoltaic solar panel applications. Tests did on the prototype show that it can contend effectively with top of the line economically accessible pyranometers at a much lower cost and with extra highlights as far as logging, estimation and remote programming. The recently created pyranometer can be utilized in any establishment where a solid estimation of solar irradiance is important, particularly whenever cost turns into a central factor while picking a pyranometer. This new pyranometer displayed in this work unites highlights which make it an aggressive option in contrast to what the market offers at present time.

\section{Acknowledgements}

The authors would like to thank the management and staff of Pan African University of Life and Earth Sciences Institute (PAULESI) for their assistance toward the payment of APC of this article.

\section{References}

[1] F. G. Hidalgo, R. F. Martinez, and E. F. Vidal, "DESIG N OF A LOW-COST SENSOR FOR SOLAR IRRADIANCE,” pp. $1-8$.

[2] M. Z.. Jacobson, "Fundamentals of Atmospheric Science," Standford Univ., 2005.

[3] M. A. Martínez, J. M. Andújar, and J. M. Enrique, "A New and Inexpensive Pyranometer for the Visible Spectral Range," pp. 4615-4634, 2009.

[4] L. C.. B. W. E. Michalsky, J. J.; Harrison, "Cosine response characteristics of some radiometric and photometric sensors," Sol. Energy 1995, vol. 4, 397-402, 1995.

[5] C. Rus-Casas, L. Hontoria, J. I. Fernández-Carrasco, G. Jiménez-Castillo, and F. Muñoz-Rodríguez, "Development of a utility model for the measurement of global radiation in photovoltaic applications in the internet of things (IoT)," Electron., vol. 8, no. 3, 2019.

[6] J. Cano, "Photovoltaic Modules: Effect of Tilt Angle on Soiling by Jose Cano A Thesis Presented in Partial Fulfillment of the Requirements for the Degree Master of Science in Technology Approved July 2011 by the Graduate Supervisory Committee : Govindasamy Tamizhm,” no. July, 2011.

[7] M. Bellis, "The history of thermometer," New York Times, 2011.

[8] I. G. Saidu et al., "Design and Implimentation of a Microcontroller Based Digital Thermometer," IOSR J. Environ. Sci. Toxicol. Food Technol., vol. 8, no. 2, pp. 119$125,2014$.

[9] M. m. h. and f. Ahmed, "Design and construction of pc based digital thermometer," ieee trans. instrum. meas., 2014.

[10] I. Dutton, E. G.; Michalsky, J. J.; Stoffel, T.; Forgan, B. W.; Hickey, J.; Alberta, T. I.; Reda, "Measurement of broadband diffuse solar irradiance using current commercial instrumentation with a correction for thermal offset errors.," $J$. Atmosph. Ocean. Tech., vol. 18, 297-31, 2001.

[11] T.. M. D. Reda, I.; Stoffel, "A method to calibrate a solar pyranometer for measuring reference diffuse irradiance.," Sol. Energy, vol. 74, 103-11, 2003.

[12] D.. King, D. L.; Myers, "Silicon-Photodiode pyranometers: operational characteristics, historical experiences, and new calibration procedures.," Proc. 26th PVSC, Anaheim, CA, USA, vol. pp. 1285-1, 1997.

[13] E. O. Doebelin, "Measurements Systems, Application and Design.," 4th ed.; McGraw Hill New York, NY, USA, Sensors, vol. 2009, 9, 2009.

[14] SRMS, "Solar Platform of the West University of Timisoara, Timisoara, Romania.," 2012.

[15] S. KE, "The shadow band correction for diffuse irradiation based on a two-component sky radiance model.," Sol Energy, vol. 39: 433-438, 1987.

[16] Reda I, "Calibration of a solar absolute cavity radiometer with traceability to the world radiometric reference.," Natl. Renew. Energy Lab. Golden, Color., vol. Tech. Rep., 1996. 